\title{
Africa-Europe Collaborations for Climate Change Research and Innovation: What Difference Have They Made?
}

\author{
James Haselip and Mike Hughes
}

Abstract This chapter critically assesses Africa-Europe collaborations on climate change research and innovation. Its authors argue that the complexity of research and innovation challenges on this topic calls for subtler collaborative and evaluation programmes. More importantly, they emphasise the need for greater harmonisation between scientific and political priorities on climate change, and point out that project goals should be more precisely defined, so as to ensure that results can be measured concretely and solutions can be progressively improved. In the absence of this clarity, they argue, climate change research and innovation programmes run the risk of being reduced to mere rhetorical statements.

Keywords Innovation $\bullet$ Scientific \& political priorities $\bullet$ Economy Climate Change $\bullet$ Societal challenges $\bullet$ Project goals $\bullet$ Outcome thinking $\bullet$ Outcome mapping • Implementation

J. Haselip ( $₫)$

UNEP DTU Partnership, Copenhagen, Denmark

M. Hughes

Ministry of Education, Kigali, Rwanda

(C) The Author(s) 2018

A. Cherry et al. (eds.), Africa-Europe Research and Innovation

Cooperation, https://doi.org/10.1007/978-3-319-69929-5_5 


\section{INTRODUCTION}

Climate change poses a major operational and strategic risk to economies, ecologies and societies across the world. The specific impacts of climate change, however, are uneven, with some regions and countries experiencing stronger disruptions than others. There are also significant differences in the ability of regions and countries to adapt to climate change: some are already on a strong footing because of their scientific and technological prowess, and others lack basic capacities in research, engineering and policy formulation. In the context of relations between Africa and the European Union (EU), there are fundamental areas of mutual interest when it comes to climate change mitigation and adaptation. These areas are reflected in high-level strategic agreements, such as the Joint AfricaEU Strategy (JAES) (African Union \& European Union 2007a), which recognise that research knowledge, and the social and technological innovation it can lead to, has a cross-cutting role to play in addressing the common strategic objectives shared by African and European countries.

In this chapter, we reflect critically on the landscape of Africa-Europe collaboration for climate change research and innovation (R\&I). Our guiding question in doing so is a deliberately searching one: what difference have these collaborations made? More specifically, we discuss three key issues: first, the extent to which Africa-Europe research partnerships on climate change have matched up to the stated bi-regional political priorities; second, how and to what extent the outputs of collaborative research have been translated into observable outcomes; and third, whether the research has influenced the direction of policy, business planning or innovation. The discussion in this chapter takes place in the context of a heightened scrutiny over the effectiveness and strategic value of international research spending as well as of development aid. As such, we aim to contribute to a wider debate about how to enhance Africa-Europe research collaboration in terms of the ability to generate and communicate information of relevance to public policymakers and the private sector (European Union 2014).

\section{Scope of Africa-Europe Research Collaboration on Climate Change}

What are the joint Africa-Europe research priorities for climate change? The answer to this question is unfortunately not a straightforward one: even though the JAES is the overarching strategy for Africa-Europe 
cooperation at a bi-regional level, extracting priority topics from the JAES and its action plans is remarkably difficult (African Union \& European Union 2007b, 2010). This is especially true for the second JAES action plan (2011-2013): the objectives and expected outcomes are very broad, with an apparent lack of coherence between the priorities stated in the overall objectives, the expected outcomes and the priority actions. The objectives, expected outcomes and priority actions are also, in some cases, closely tied to or presented as concrete projects, which, in turn, add to an unclear presentation. ${ }^{1}$ Furthermore, when we survey the scope of the portfolio of Africa-EU collaboration projects funded by the EU Framework Programme (FP), there seems to be an imbalance between the political priorities expressed through the JAES (to the extent that these can be derived) and actual research. The lack of a clear statement of joint priorities on climate change presents a fundamental challenge to the task of assessing bi-regional climate change research projects against the stated political priorities.

An attempt at highlighting some of the priority topics in the JAES can however be made by taking the priority actions listed in the action plans as representative of bi-regional priorities. Using this approach, the relevant topics on climate change emerged as:

- Desertification

- Climate information and earth observation

- Adaptation

- Forests

- The capacity of African negotiators

- Disaster risk reduction

- Biodiversity conservation

- Natural resource management

- Adaptation and mitigation strategies

- Carbon markets

- Climate-friendly technologies

Extracting political priority topics from the action plans does, however, run the risk of excluding topics that are integrated in each priority action. For example, this could be true for a topic like water. Water is not highlighted as a priority in either of the plans. It is however mentioned as forming part of one of the activities in the African Monitoring of the Environment for Sustainable Development project ("Enhancing the African capacities for the operational monitoring of climate change and 
variability, vegetation, water resources, land degradation, carbon dioxide emissions, etc.”) (African Union \& European Union 2010, p. 49). While water may be widely viewed as a "big issue", it is mentioned in the JAES in but a single bullet point, for one activity, and under just one priority action. This leads us to conclude that water is not a top priority in the JAES.

For our analysis in this chapter, of the topics covered in bi-regional climate change research, and how these relate to the political priorities, we have used the topics listed above as a starting point. To arrive at an overview of Africa-EU bi-regional climate change research projects, we screened 41 relevant FP6 and FP7 projects, and then conducted interviews with managers from 7 projects (see CAAST-Net Plus 2014). ${ }^{2}$ The 41 projects we selected were categorised in terms of their primary focus: climate change mitigation, adaptation or both (see Fig. 5.1).

It is evident that there has been more emphasis on adaptation than mitigation or adaptation/mitigation projects in Africa-EU research collaboration on climate change. The split demonstrates a degree of

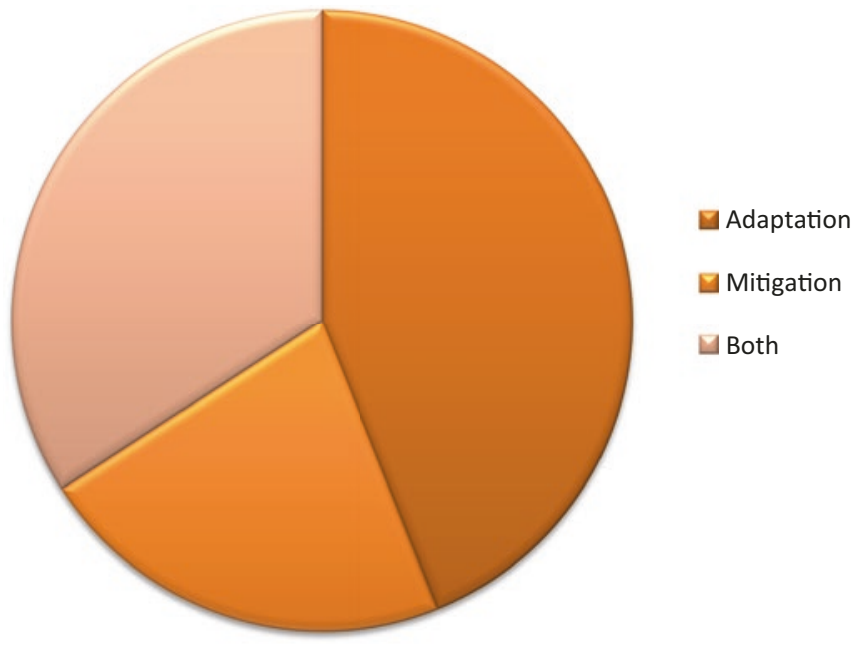

Fig. 5.1 Division of FP6 and FP7 projects according to overall topics (Source: CAAST-Net Plus 2014, p. 5) 
coherence between funded projects and the list of bi-regional priority topics, in this case adaptation.

The division between adaptation and mitigation projects, in terms of the size of EU funding, reveals a slightly different picture. On average, mitigation projects received approximately 9.1 million euros per project, while adaptation projects have an average budget of about 6.3 million euros. Projects covering both adaptation and mitigation have even smaller budgets, averaging 5.2 million euros per project. Overall, there is still more FP finance directed towards adaptation than mitigation (Fig. 5.2).

The 41 projects were also divided according to the priority topics given above, some of which cover both mitigation and adaptation issues. In the categorisation of projects in this way, none of the topics are mutually exclusive, meaning that one project can cover several topics. This does not, however, count for the "Other" category, which only includes projects that do not cover any of the other topics:

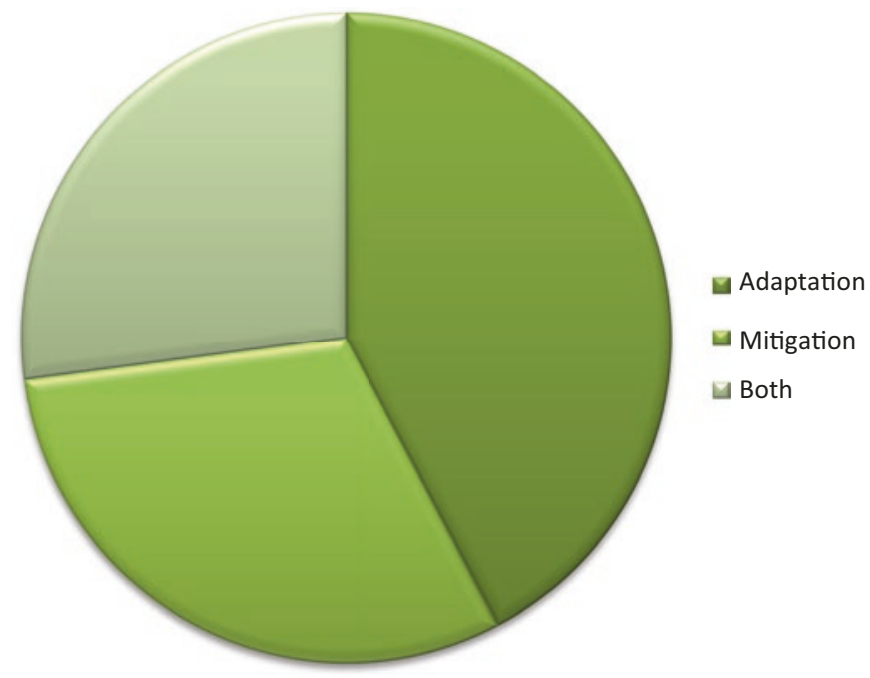

Fig. 5.2 Share of FP6 and FP7 funding spend on adaptation/mitigation (Source: CAAST-Net Plus 2014, p. 5) 


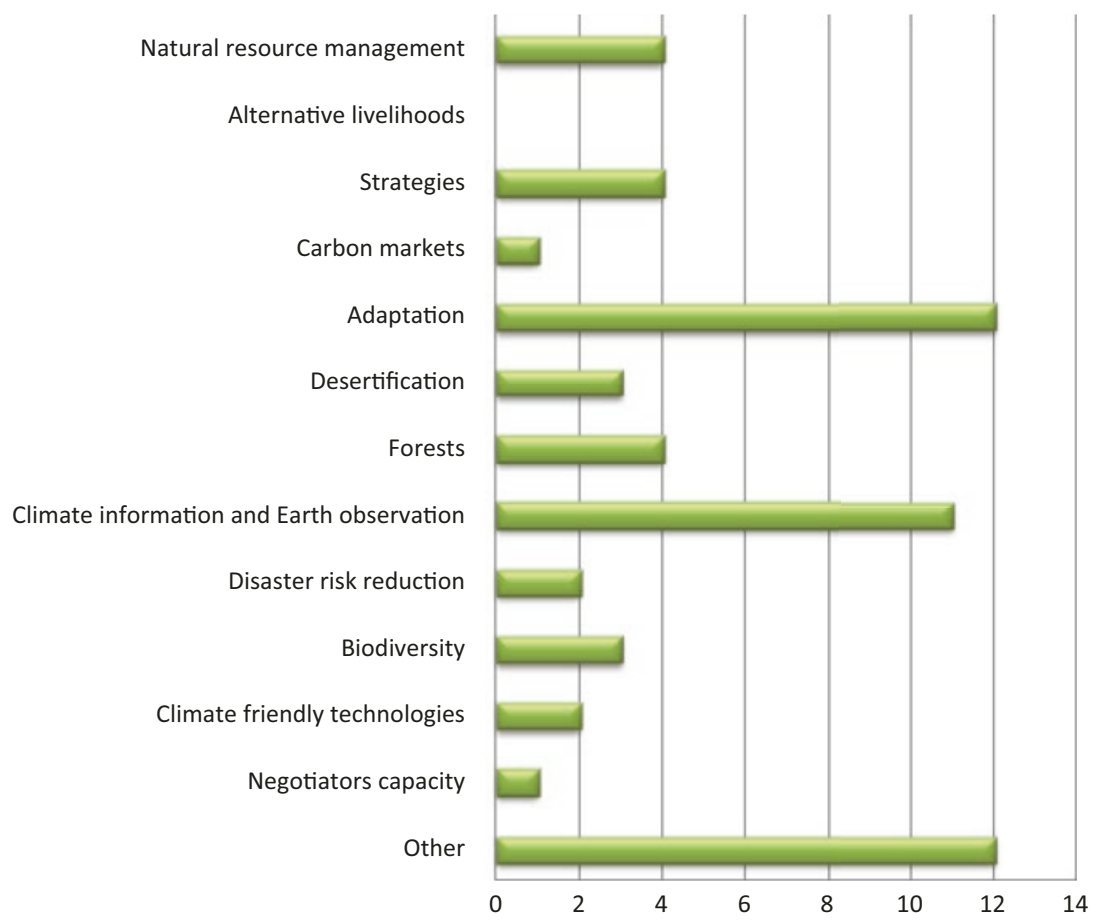

Fig. 5.3 Number of projects in each JAES priority category (Source: CAASTNet Plus 2014, p. 5)

According to Fig. 5.3, less than one-third of the projects do not explicitly cover any of the priority topics extracted from the second JAES action plan. Several of these projects, which were categorised as "Other", have an explicit focus on water or agriculture, which, as stated above, do not seem to be prioritised in the second action plan of the JAES.

If water and agriculture are included as topics in the categorisation, the distribution looks different. Figure 5.4 indicates that these topics are in fact very prominent in the bi-regional climate change research environment. This is especially true for water, which is included as a focus area in almost half of the projects investigated in the research reflected in this chapter. 


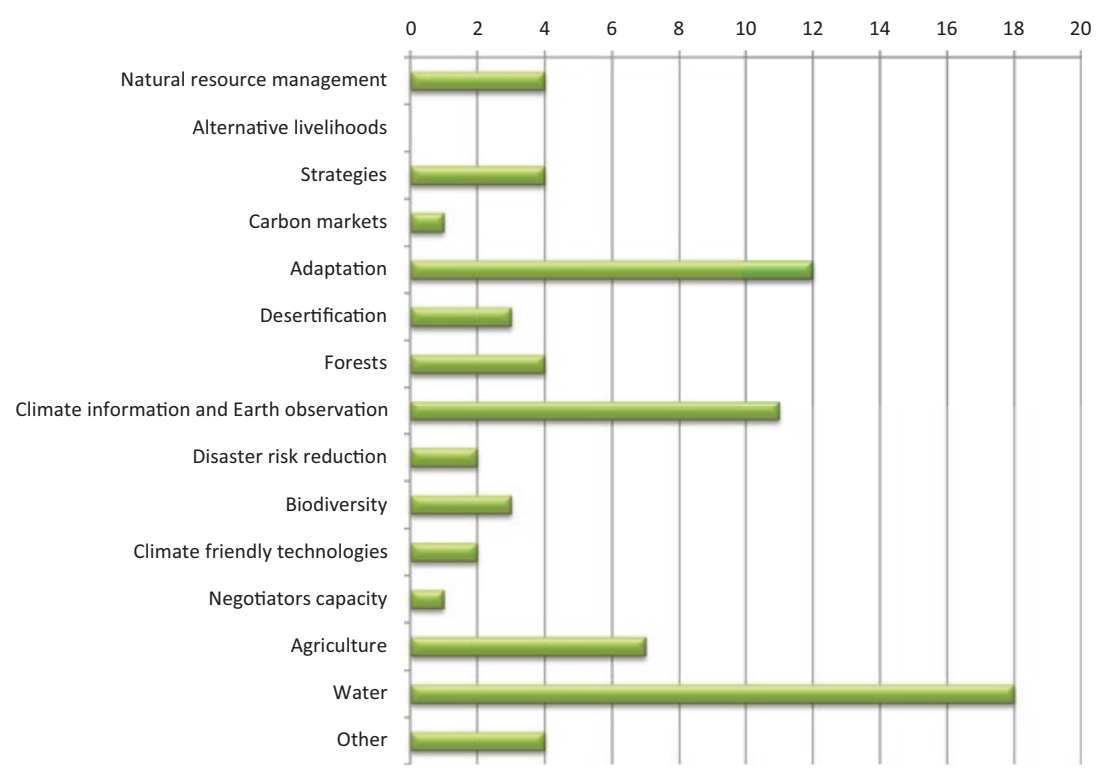

Fig. 5.4 Number of projects in each JAES priority category (including water and agriculture) (Source: CAAST-Net Plus 2014, p. 5)

This thematic focus correlates poorly with the JAES action plans for climate change, which, at best, have a secondary focus on water and agriculture. It is also important to note that a topic such as adaptation covers a wide range of different projects with different thematic emphases, not all of which are listed in the priority topics of the second JAES action plan. As such, there seems to be an imbalance between the political priorities and the actual research conducted, partly explained by the fact that the FP6 predates the JAES. While some of the political priorities are well covered by research, others, like carbon markets, negotiator capacity, disaster risk reduction and climate friendly technologies, are not at all prominent in bi-regional research on climate change.

In drawing these conclusions, it is important to take into account the time lag between the adoption of a political strategy and its manifestation in research projects. This is especially the case for our analysis in this 
chapter: the JAES action plans cover the period from 2008 to 2013, whereas some of the projects analysed date as far back as 2004. In addition, while we take the list of topics at face value, it is perhaps naïve to assume that there has been any conscious effort on behalf of project developers to interpret or otherwise respond to the JAES priorities. Nonetheless, it is important to know whether there exists a thematic overlap, by accident or design.

\section{Outcomes of Bi-regional Climate Change Research Collaboration}

The research-output-outcome chain can be seen as comprising a series of stages, starting with research design and the identification of specific user constituencies and the public at large. Dissemination could be directed at policymakers, and further onwards to various categories of practitioners. The interface with policymakers could lead to policy change or improvement. In turn, policy change or influence could lead to uptake by practitioners and users. Only the end result of these convoluted processes could qualify for the term "impact". Owing to their complexity, outcomes are usually better represented through narratives. Generic indicators or quantitative measures can only count outputs that in themselves are of little meaning in terms of pointing to the ultimate impacts of a particular initiative. In this sense, we draw in this chapter on the so-called outcome mapping school of thought (see www.outcomemapping.ca, 2017).

In order to investigate the difference that any given project or intervention has made, it is useful to first document the intended impacts, as conceived and pursued by project managers. When research projects are granted funding under the FP, for example, project descriptions usually contain statements of expected "impact" that is used as a criterion of project assessment. We asked respondents to describe the expected impacts of their projects, as defined at the start of the project. They were also asked if and how they tried to measure impacts and, the means or methods employed. Furthermore, we asked if they were able to plausibly attribute the observed "impact" to their specific research project, rather than to other intervening factors. We wanted explanations of how these outcomes occurred, that is, we asked: What was the "mechanism of change" at work during and after project implementation? With this type of investigation outcomes can only be linked to a specific activities through plausible claims 
(i.e. reasonable arguments provided by stakeholders as to the cause-andeffect relationship between the identified research project and a given policy, practice or behaviour).

In the case of the African Monsoon Multidisciplinary Analysis (AMMA) project, the following bullet points are the closest to a statement of intended impacts:

- To assist in the achievement of the United Nations (UN) Millennium Development Goals (MDGs) in Africa and the implementation of the EU Strategy for Africa, which includes "action to counter the effects of climate change" and "the development of local capabilities to generate reliable information on the location, condition and evolution of environmental resources, food availability and crisis situations"

- Add to the African participation and ownership of AMMA research activities, and strengthen the linkages between European research institutions and the West African research community

- Ensure that the further development of national expertise is maintained beyond the AMMA project

While such statements sound plausible and convincing, they serve mostly to highlight the topical relevance of the research. Indeed, according to Jan Polcher, European leader of the AMMA project, "the impact section of the proposal was very much political talk" (CAAST-Net Plus 2014 , p. 32). Similarly, the major anticipated outcomes of the FP7 project ClimAfrica focused on:

- Responding to environmental degradation as relevant for poverty alleviation and food security enhancement

- Specific climate change mitigation and adaptation options for local communities

- Capacity of team members and other stakeholders within the communities enhanced

- Synergies with existing actors (NGOs, district assembly etc.) in the various localities strengthened

These typically vague statements of intended impact are difficult to measure, or verify. Ernest Ohene Asare of the Department of Physics at the Kwame Nkrumah University of Science and Technology (KNUST) in Ghana, which is also a "beneficiary" of the AMMA and QWeCI 
(Quantifying Weather and Climate Impacts on Health in Developing Countries) projects, offered a more concrete account of observation outcomes. Project funds, Ohene Asare said, were invested in the acquisition of instruments needed for data collection and therefore better data were collected for the AMMA and QWeCI projects (CAAST-Net Plus 2014, p. 32). Specifically, he worked on a malarial model to be used in Ghana with partners from University of Cologne, Germany, and the International Centre for Theoretical Physics, Italy, and is currently working to improve understanding of the breeding temperature of mosquitoes with the help of colleagues at KNUST.

Ohene Asare stated that the project helped him to "get exposure" and that he was able to work with other scientists, which also enhanced project work and gave new directions. He added that his presentation skills improved and that he learned how to communicate and disseminate the results of scholarly work through tailor-made presentations, personal discussions and formal interviews. More importantly, the two projects have brought together scientists from a range of disciplines and have fostered networking and knowledge sharing. While this account is more concrete, it nevertheless falls short of responding to the project's statements of intended impacts, and rather provides an anecdotal basis for attributing project outcomes.

The AFROMAISON project makes reference to "impact pathways", developed at the beginning of the project. In this approach, potential impacts are identified, elaborating the mechanism of change in a participatory manner by involving key stakeholders from the outset. As the project managers noted, this serves as a guide to implementation, a means for periodically checking whether the "impact theory" is correct, and making adjustments during implementation. If properly followed, this appears to be an effective approach for enabling the identification of realistic outcomes and how the project outputs can lead to these. Generally speaking, the articulation of impact pathways is considered to be part of the challenge of enhancing the ownership of tools and empowerment of the subnational authorities and communities.

In Uganda, the AFROMAISON project developed scenarios to understand the extent to which human activities had an impact on the natural resources and ultimately on the climate in the Rwenzori mountains/ Albertine region. The approach taken was through "action research", where the project team and communities met to share experiences and agree on practical solutions for pertinent natural resource management (NRM) challenges like landslides, silting of rivers and floods. These 
scenarios served as both awareness raising tools and consensus building platforms for effective NRM. They also helped to ensure that research results were acceptable and directly beneficial to the target community. A key project output was the development of a participatory tool, "Mpang'ame", a simulation game that helps stakeholders identify and reflect on appropriate actions for better NRM practices. At the local level, the game was disseminated to schools, vocational institutions, local government leaders and policymakers within various fora. At regional and international levels, the game was disseminated at meetings for AFROMAISON partners and NRM stakeholders in Burkina Faso, Ethiopia, Mali, South Africa, Tunisia, as well as to graduate students in France, on special request from university administrators. Other dissemination channels included articles published in the International Journal of Innovation Sciences, book chapters, brochures, leaflets and the project website.

According to Arseni Semana, principal investigator of AFROMAISON in Uganda, the main challenges that the project encountered were related to the attitudes of the communities (CAAST-Net Plus 2014, p. 32). There was slow adoption of integrated NRM practices mainly because of the commercial culture that has emerged within the beneficiary communities. NGOs facilitate communities' participation in NRM planning and implementation. As a result, it is almost impossible to engage the communities without attaching a monetary incentive. Private sector involvement is still minimal and participating private sector players are mainly informal and micro. Nonetheless, the project held a consultative meeting between the ministries of agriculture, animal industry and fisheries, and water and environment to enhance policy level integration of NRM using tools from the research. This constitutes a more valuable, critically reflective account of the relationship between the project's outputs and outcomes, and one which integrates key contextual factors to explain the barriers and constraints to achieving the intended impacts.

Overall, we a found that statements of "intended impact" are often more akin to aspirations expressed by project designers and managers. In most cases, these aspirations do little more than offer rhetorical support to wider climate and development targets, such as the MDGs. As such, there is generally no explicit explanation of how these impacts can-even theoretically-be achieved. Instead, there is a significant level of assumed attribution; that is, broad statements about how the research project's focus relates to the wider issues and how it contributes knowledge necessary to tackle these challenges vis-à-vis the stated aims and objectives. 
We also found that very few FP projects make clear distinctions between outputs, outcomes and impacts at the design stage. Consequently, the terms are often confused or used interchangeably. The most common mistake is to present and refer to project outputs (workshops, research articles, policy papers, conferences etc.) as outcomes. Similarly, there is an overreferencing by project designers who, in outlining their activities, indicate "engagement with a variety of stakeholders" as key. This is simply another rhetorical device that, while politically correct and plausible, is rarely explained in detail and hence fails to substantiate a convincing theory, or set of mechanisms, for actual change.

While our interview schedule placed a sharp emphasis on understanding how outcomes and impacts were understood and anticipated, our questions often proved difficult for respondents to answer. The latter often drifted towards a focus on more procedural and "mundane" aspects of Africa-EU research collaborations, including the challenges of day-today management and the ultimate delivery of project outputs. Or they focused on the challenges of coordination and of targeting key project conclusions or recommendations to the most appropriate audiences. If they did manage to engage with "target audiences", then there was often little or no follow-up that would enable project managers to understand the extent to which these key messages had influenced policymakers or the business community. Information and knowledge in this regard remain anecdotal, at best. It was also a challenge to receive concrete examples of "outcomes", as understood in outcome mapping analysis, which many respondents confused with "outputs". This is a fundamental issue and one that appears to explain the paucity of plausible arguments to attribute project outputs to demonstrable outcomes.

\section{Engaging and Influencing Public and Private Decision Makers in Africa And the EU}

To what extent have the research and development outputs from AfricaEU climate change collaboration, funded by FP6 and FP7, informed public policymaking and business planning? It is widely acknowledged that applying technical knowledge to policy and business planning is a key challenge. But what do we know about the barriers and constraints to such uptake? How can these be removed? We attempted to answer these questions by analysing responses from government, civil society and commercial 
actors. Our concerns centred on the issues faced in specific projects, such as: What were the main challenges in communicating research to a policy and business audience? Did project partners interact with policymakers? If so, did these actors adopt the research findings as evidence in support of their policy formulation or revision, and how did they ascertain whether they did so or not? If they did not embrace the research findings, what was the reason?

Principal investigator of the AMMA and QWeCI projects in Ghana, Sylvester K. Danuor of the physics department of KNUST, said that in order to achieve the project's intended impacts, research findings were disseminated mainly at conferences and workshops, and through journal articles. According to Danuor, workshops were the most effective means of reaching out to the intended beneficiaries. These included the research community, policymakers and civil society organisations. He and other interviewees were of the view that the AMMA and QWeCI projects "had some interaction" with policymakers who "embraced the research findings" (CAAST-Net Plus 2014, p. 32). However, this was yet to be reflected in official policy formulations. For instance, there were meetings with the Ghana Meteorological Agency and the District Health Directorates through the Metropolitan Health Directorate of the Ministry of Health. There was a similar positive interaction with civil society organisations with a view to encouraging them to make use of the project's findings in policy formulation and activities.

This account of project-policy interactions is typical of the responses we received. These responses reveal a high degree of uncertainty and inability to verify the claims, however plausible they appear. As already mentioned, this reflects a lack of "outcome thinking" at the level of research project design and management. In short, there was a predominant focus by project managers on outputs that are easy to document and report. Where an interaction with policymakers is mentioned, the precise mechanism through which research outputs actually influence policy or practice is rarely explained in any detail. As such, efforts to engage with and influence policymakers are mostly $a d$ hoc at best, and amount to little more than a hope or expectation that the research findings will be accessed, understood and taken up by the relevant actors in government or the private sector. In turn, the lack of clear mechanisms or theories of change undermines efforts to reflect on the project implementation process or face the hard question of what difference their efforts made. Finally, there 
is also a general lack of follow-up studies to monitor longer-term outcomes of framework research projects, which once again reflects the predominant focus on monitoring, reporting and evaluating the strength of project outputs.

In the realm of private sector engagement, there is minimal evidence of FP6 and FP7 research projects generating climate change knowledge that feeds directly into technology development or patents. ${ }^{3}$ We would, however, expect to gather at least some anecdotal evidence of positive relationships between research projects and technology developers and/or private sector investors operating in the market for clean and low-carbon technology. To a large extent this lack of obvious examples reflects the thematic focus of many FP-funded projects on climate change: the majority focus on the generation of basic research knowledge, such as emissions monitoring and data analysis, or capacity building, which does not have a strong or obvious commercial application. As such, there are generally low levels of private sector involvement in Africa-Europe research collaborations on climate change, which, by extension, appears to suggest that the FP has had limited success in supporting innovation.

While it may not be easy to identify a clear attribution between AfricaEU research collaborations on private sector innovation and technology development, it does not mean that it does not occur. Indeed, it is far more likely that private sector actors will be drawing on the findings of such research collaborations in the preparation of their business plans, given they have a clear and strong incentive to develop their business and investment intention upon scientifically sound findings. The fact that most FP-funded research findings are publically available would make this even more likely, though the project managers and partners would be unaware of this information uptake.

Another issue that may constrain the active promotion of FP-funded research findings into public and private (non-research) forums is the lack of ability or willingness by project managers to actively engage with such decision makers. In the case of climate change research all the recent framework projects are managed by European-based institutes. This fact may be of material consequence in terms of their limited contact-that is, apart from via project partners - with local policymaking and business leader networks. There may also be reluctance on the part of Europeans to get involved with local policymaking and politics. Project managers are likely to be unfamiliar with the complex institutional and policy terrain of 
African countries. As Jan Polcher, the European-based manager of the AMMA project, observed:

our main targets were the local scientific community and the operational agencies [...].[However] it is my belief that Western scientists have no role in disseminating to policymakers; civil society organisations; politicians; private sector in West Africa. Because of the colonial heritage our message would not have the desired impact. So this dissemination is to be left to the regional research community. (CAAST-Net Plus 2014, p. 32)

This is an unusually frank but significant admission by a project manager who would in principle be responsible for pushing the research-topolicy connections. It raises more questions about whether the research-to-policy agenda is being advanced in the first place, despite the broad statements of intended impact mentioned in the project documents.

Many of the respondents in this aspect of our research focused on the difficulty of directing conclusions or recommendations at most appropriate audiences. If and when they did manage to engage with target audiences, then there was often little or no follow-up that would enable project managers to understand the extent to which these key messages had influenced policymakers or the business community. Knowledge in this regard remains anecdotal, at best.

\section{Conclusion}

Even though the JAES is supposed to be the overarching strategy for Africa-Europe cooperation at bi-regional level, extracting specific climate change research priority topics from past JAES action plans proved difficult. The plans should not therefore necessarily be seen as the guiding document for bi-regional research on climate change. What this chapter also showed is that the theories of change inherent in most FP-funded projects-to the extent they are made explicit-are too simplistic and depend upon linear concepts, as manifested in the predominant logframe approach to project design and management. There appears to be a low level of outcome thinking to the extent that many respondents confused project outcomes with project outputs. This is a fundamental issue for Africa-EU research collaborations across thematic areas, and one that appears to explain the paucity of plausible arguments to attribute project outputs to demonstrable outcomes in the context of the collaboration on climate change studied in this chapter. 
Furthermore, this chapter argues that statements of intended impact are often tantamount to mere aspirations expressed by project designers and managers, which in most cases do little more than offer rhetorical support to wider climate and development targets, such as the former MDGs. As such there is generally no explicit explanation of how these impacts can, even theoretically, be achieved. Instead, there is a significant level of assumed attribution, that is, broad statements of how the research project's focus relates to the wider issues and how it contributes knowledge necessary to tackle these challenges $v i s-\grave{a}$-vis the projects' aims and objectives. Similarly, there is too much reference to projects aiming to achieve their stated aims and impacts by engaging with a variety of stakeholders, another rhetorical device that is at once politically correct and plausible, though rarely explained in detail and hence fails to provide a convincing theory, or mechanism, of change. Such a lack undermines efforts to reflect upon the project implementation process and to answer the question "what difference did it make?"

\section{Notes}

1. Cases in point include the Great Green Wall of the Sahara and Sahel Initiative, ClimDev, African Monitoring of the Environment for Sustainable Development and the Global Climate Change Alliance.

2. The projects included AFROMAISON, AMMA, Animal Change, ClimAfrica, DEWFORA, Healthy Futures and QWECI.

3. It should be acknowledged that this finding is based on an in-depth questioning of a small sample of projects, so caution should be taken in drawing programme-wide conclusions.

\section{REFERENCES}

African Union \& European Union. (2007a). The Africa-EU strategic partnership: A joint Africa-EU strategy. Available from: http://www.africa-eu-partnership. org/sites/default/files/documents/eas2007_joint_strategy_en.pdf. Accessed 8 May 2017.

African Union \& European Union. (2007b). First action plan (2008-2010) for the implementation of the Africa-EU strategic partnership. Available from: http:// www.africa-eu-partnership.org/sites/default/files/documents/jaes_action_ plan_2008-2010.pdf. Accessed 8 May 2017.

African Union \& European Union. (2010). Joint Africa-EU strategy: Action plan 2011-2013. Available from: http://www.africa-eu-partnership.org/sites/ default/files/documents/03-JAES_action_plan_en.pdf. Accessed 8 May 2017. 
CAAST-Net Plus. (2014). Africa-EU research collaboration on climate change: A critical analysis of the scope, coordination and uptake of findings. Cape Town: Research Africa.

European Union. (2014). Mapping of best practice regional and multi-country cooperative STI initiatives between Africa and Europe: Identification of financial mechanisms 2008-2012. Luxembourg: Publications Office of the European Union.

Open Access This chapter is licensed under the terms of the Creative Commons Attribution 4.0 International License (http://creativecommons.org/licenses/ by $/ 4.0 /)$, which permits use, sharing, adaptation, distribution and reproduction in any medium or format, as long as you give appropriate credit to the original author(s) and the source, provide a link to the Creative Commons license and indicate if changes were made.

The images or other third party material in this chapter are included in the chapter's Creative Commons license, unless indicated otherwise in a credit line to the material. If material is not included in the chapter's Creative Commons license and your intended use is not permitted by statutory regulation or exceeds the permitted use, you will need to obtain permission directly from the copyright holder.

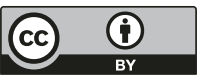

